\title{
Measuring Potency Among Preschool Children: Instruments and Intervention
}

\section{Rachel Lev-Wiesel, Avi Besser, and Renana Laish}

\begin{abstract}
This study explored the impact of Potency-Focused Intervention among preschool children using a prospective research design. To achieve this aim, an instrument (the Child Adaptation Measure of Potency, or CAMP) was developed to examine the construct of potency among this population. The psychometric properties of this new CAMP scale was analyzed among 90 preschool children and the scale was proven to be both reliable and valid. Sixty-six children participated in the intervention study itself: thirty-two children participated in an intensive intervention program while the remaining children served as a control group. The results indicate that Potency-Focused intervention significantly enhanced potency among children in the intervention group, though it did not enhance the quality of self-concept. This finding suggests that while potency and self-concept are similar in some respects, they are separate constructs. The implications of Potency-Focused intervention among preschool children are discussed.
\end{abstract}

KEY WORDS: Potency Scale; Adaptation; Potency-Focused Intervention; Preschool-Children.

The child's personal resources such as self-control, self-confidence, and social support (e.g., Antonovsky, 1991; Frazer, 1997) are thought to be significant protective factors in the child's successful adaptation to the challenges and demands faced in school. School failure might have severe consequences for children (Hepburn \& White, 1990; Richman \& Bown, 1997). In this respect, it can be

Rachel Lev-Wiesel and Renana Laish are affiliated with the Department of Social Work, Ben-Gurion University of the Negev, Israel. Avi Besser is affiliated with the Department of Behavioral Sciences, Sapir Academic College, D.N. Hof Ashkeoln 79165, Israel.

Address correspondence to Rachel Lev-Wiesel, Ph.D., Associate Professor, Department of Social Work, Ben-Gurion University of the Negev, P.O. Box 653, 84105, Beer-Sheva, Israel; e-mail: rachellv@bgumail.bgu.ac.il 
assumed that the child's personal and social resources prior to his/ her school entry would effect his/her academic and social success in school. Thus, knowing the extent to which the preschooler feels able to cope with the demands of life will enable educators to develop goal-oriented interventions aimed at enhancing the child's personal resources prior to starting school.

There are a number of instruments available for the assessment of elementary school children personal resources such as the Sense of Coherence Scale (Antonovsky, 1980), the Self-Perception Profile for Children (Harter, 1982), the Perceived Competence Scale for Adolescents (Harter, 1988), and the Primary Nowicki-Strickland Internal-External Control Scale (PPNS-IE, Nowicki \& Duke, 1974). However, there are only a few scales for preschool children that specifically target personal resources (e.g., the Learner Self-Concept Test; DiLorenzo, 1975). The aim of the present study was to develop an instrument for assessing preschool children's personal resources.

One of the personal resources known to reduce the long-term psychological and physiological effects of life stresses is potency, defined by Ben-Sira (1985) as one's self-control (based on Rotter's concept of locus of control), self confidence and the belief in the existence of social support (Amir \& Lev-Wiesel, 2000; Ben-Sira, 1991; Lev-Wiesel $\&$ Amir, 2000). The Potency Scale developed by Ben-Sira (1985) was found to be a valid measure for assessing adults' self-control, selfconfidence and the belief in the existence of social support. The present paper reports the results of two studies: (a) The validation of a potency scale for preschool children, and (b) The assessment of potency-focused intervention effect in preschool students.

\section{The Role of Personal Resources in Coping with Stress}

Most approaches to stress state that, regardless of age, people are continuously confronted with demands from their internal and external environments (Antonovsky, 1979; Monat \& Lazarus, 1991). These demands must be coped with, by means of the personal resources individuals have at their disposal. Some demands are met automatically and effortlessly, while others may be inadequately met, or met with difficulty, due to a lack of coping resources. The latter are likely to arouse tension, and therefore may be regarded as stressors. Psychological well-being is contingent on the maintenance of emotional homeostasis, and/or its re-establishment following 
disruption due to a failure to cope adequately with stressors. Re-establishment of emotional homeostasis is conceptualized as readjustment, whereas prolonged failure to regain emotional balance is conceptualized as an ongoing state of stress (Antonovsky, 1979). The degree of stress experienced is dependent on the extent to which the individual perceives the stressor as threatening, and estimates his/her ability to cope. Thus, the degree of stress experienced by different individuals in response to the same stressor may differ accordingly (Cox, 1978; Folkman \& Lazarus, 1991).

Coping with stressors is achieved by utilizing of the personal, social and material resources individuals have at their disposal. Personal resources are defined as the internal strengths individuals have that enable them to cope with unfamiliar events or tasks (BenSira, 1993; Lazarus \& Folkman, 1984). Personal resources reflect the general belief a person has regarding his/her ability to cope with external and internal demands. Personal resources include aspects of the personality and skills such as self-control (Pearlin, 1991), hardiness (Kobasa, 1979), locus of control (Rotter, 1966), sense of coherence (Antonovsky, 1979) and potency (Ben-Sira, 1985). Social resources are those resources available to the individual from his or her primary environment (e.g., relatives) or secondary environment (e.g., professionals: Ben-Sira, 1991).

\section{Potency: A Personality Resource}

Ben-Sira (1985) defines potency as a two-part quality; the first aspect of potency consists of an enduring confidence in one's own capabilities and locus of control-taking responsibility over one's actions (Rotter, 1966). The second aspect of potency reflects the individual's commitment to the social environment, which is perceived as basically meaningful, predictable, and characterized by a reliable and just distribution of rewards. This conception of potency is based on the assumption that successfully meeting demands is not dependent solely on the individual's abilities per se, but must be seen in context of the perceived social environment (Lewin, 1951; Shuval, 1957). In operational terms, potency comprises self-appreciation and mastery on the one hand, and commitment to a meaningful, orderly society on the other. Thus, potency facilitates reequilibration following an unmet demand, either by calling forth experience-based confidence that a solution is bound to come up, or by reassessing the 
relative importance of that particular failure. The notion of potency according to Ben-Sira (1985) illuminates the significance of a person's conception of society as a crucial factor in the coping process. This means the belief in the existence of social support which enables the use of social support networks in times of need. Unlike other personal resources, potency includes both the individual's view of himself/herself as well as of society. Potency is also thought to differ from other personal resources in terms of when it is activated. Other resources are held to be activated when confronting and resolving demands; for example, self-efficacy, or confidence in one's coping capacities (Bandura, 1982) leads individuals to try to master challenges. Another resource that is activated when confronting demands is sense of coherence, which includes a recognition that even catastrophic events are comprehensible and that life experiences are manageable and meaningful (Antonovsky, 1979, 1987), and promotes an active search for meaning during threatening events. Potency, on the other hand, is conceived as a tension-resolving mechanism activated by the initial failure of other resources to meet a demand. In relation to the present study, potency was assumed to protect preschool children from falling into the trap of a learned helplessness phenomena (Seligman, 1975) when coping with academic or social failure.

\section{Method}

\section{Sample}

Two independent samples were selected. The first sample was selected to validate the instrument developed, namely, the Child Adaptation Measure of Potency (CAMP). The second sample was selected to evaluate the Potency-Focused Intervention program. The characteristics of each sample are described in the procedure section for each study.

\section{Measures}

The Learner Self-Concept Test (LSCT; DiLorenzo, 1975). The LSCT served as a measure of convergent validity for the CAMP. The LSCT was chosen because it evaluates a construct that, while not identical 
to potency, is very similar. Self-concept is defined as the way one perceives himself/herself, and assesses personal characteristics and abilities as compared to others (Rogers, 1951). Self-concept develops as the result of early life experiences (Felker, 1979; Wilie, 1961) especially with parental figures (Coopersmith, 1967; Webster \& Sobiezek, 1967; Yamamoto, 1972). Both self-concept and potency are learned constructs of perceptions, attitudes and values. However, parental figures are thought to play the most significant role in the development of self-concept, whereas other social figures and the wider social environment are thought to impact the development of a sense of potency. Because they measure related constructs, a positive correlation would be expected between the two instruments.

The LSCT (designed for the 4-6 age range) comprises 12 items. Each includes, (a) one or two drawings representing a particular classroom situation and (b) a series of two questions used to elicit responses to the drawings. The procedure for administration of the LSCT involves presenting the drawing to the child, and noting the positive and negative characteristics the child assigns to each drawing. The child describes the characters in a drawing in terms of their personal attributes. Total scores are based on the number of positive responses minus the number of negative responses. The greater the number of positive responses, the better the subject's self-concept is held to be. This measure has been shown to be valid for assessing self-concept in a variety of populations worldwide (DiLorenzo, 1975). In the present study, the Cronbach $\alpha$ internal consistency coefficient was .87 across the 12 items in the LSCT scale.

\section{The Child Adaptation Measure of Potency (CAMP)}

The CAMP was adapted from the original Potency Scale (Ben-Sira, 1985) used for adult populations, which requires knowledge of reading and writing. The Potency Scale was found to have high validity and reliability (test-retest) in 1200 Israeli households drawn randomly from the Israeli voting register, and 3- sampled groups consisting of psychiatric patients (Israelis and Americans) and mentally healthy individuals. The Potency Scale comprises 19 statements assessing 4 personal qualities. These qualities are: self-confidence (e.g., "I am able to do things as well as most other people"); mastery (e.g., "I have little control over things that happen to me"; "I feel that I am pushed around in life"); alienation, defined as the opposite 
of commitment (e.g., "nowadays a person has to live pretty much for today and let tomorrow take care of itself"; "having the right connections is more important than talent if you want to achieve something"); and anonymity, defined as the opposite of a sense of meaning and justice (e.g., "community leaders are indifferent to one's needs"; "my life goals are receding rather than being realized"). Respondents are asked to rate their agreement with each statement on a 6-point scale, ranging from "not at all" (1) to "very much" (6). The Potency Scale has been found to have high levels of validity and reliability in a large range of populations (Ben-Sira, 1985).

\section{Adaptation Procedure}

The 19 items of the original potency scale were modified to reflect the life experience and developmental language stage of preschoolaged children. In addition, a dichotic (yes/no) oral response was substituted for ratings on the 6-point scale (see Appendix I). These modifications reduced testing time, resulting in an instrument that could be verbally administered quickly by educators and practitioners. In order to assess content validity, the CAMP was given to two practitioners who served as judges of the test items, and was administered to two (a girl and a boy) 5-year-old children randomly selected. The adult judges were provided with a definition of "potency," and were asked to rate each item on the scale according to the extent to which it reflected this definition $(0-100 \%)$. The scale was administered individually to each child after the judge's ratings. The child's comprehension of each item was evaluated by both the interviewer (a child psychologist) and the present investigators. The final version of the test included only items that were rated by both judges to represent potency at $100 \%$. Items receiving lower ratings on the initial scale were modified and given again to the judges for scoring, and to new children for evaluation of comprehension. The final items and the psychometrics properties of each are presented in Appendix I.

\section{Validation of the Child Adaptation Measure of Potency (CAMP)}

The initial validation of the CAMP was carried out on a sample of 90 children (44 girls and 46 boys) with a mean age of 5 years and 4 
months, $(\mathrm{SD}=.76)(M=5.54, \mathrm{SD}=.77$, and $M=5.24, \mathrm{SD}=.75$ for boys and girls respectively). The mean age did not differ among boys and girls. The children were randomly sampled from 10 kindergartens in a lower middle-class urban area of Israel.

Three validation procedures were employed to assess content validity: the initial inter-judge evaluation (as described in the Method section), a factor analysis across test items, and a convergent validity analysis carried out between the CAMP and the LSCT. After the inter-judge procedures for the content validity acceptability, the final CAMP revealed an internal consistency coefficient Cronbach $\alpha$ of .86 across the 19 test items. In the second procedure, the children's scores on the 19 test items were subject to an orthogonal principal component Factor Analysis with Varimax rotation. This analysis revealed that one factor accounted for $32 \%$ of the total variance (Eigen value $=5.92,>1$ ). On the basis of these results, a single "potency" score was computed for each participant. This score was used in the subsequent analyses. (See Appendix I for a table of the factor loading, and Items means and standard deviations.)

In the third procedure, correlations were carried out between the LSCT and the CAMP in order to determine whether the two instruments assessed similar constructs (i.e., convergent validity). A significant positive correlation was obtained between the two measures, $(r=.54, p<.001)$.

\section{Pre- and Post-Intervention: Group Discriminate Validity}

Upon completion of the above validation procedures, pre- and posttest scores were obtained on a sample of preschool children using a longitudinal research design. The sample comprised two groups of children: The first group underwent an intervention program aimed at increasing potency while the second served as a control group. The primary aim in this context was to obtain a validity coefficient for the CAMP, as well as test-retest estimates of reliability, in the intervention group. Pre-intervention scores on the CAMP served as the criterion, and post-intervention scores indicated whether the CAMP was indeed sensitive to changes in potency. The control group provided the measure of test-retest reliability.

The sample comprised 66 children ( 31 girls and 35 boys) from two kindergartens located in a lower middle-class urban center in Israel. The kindergartens were randomly sampled from 12 kindergartens 
matched on demographic and socioeconomic variables. The two kindergartens were randomly assigned to serve as the intervention and control groups. The intervention group comprised 32 children (48\%), and the comparison group 34 children $(52 \%)$. The mean age of the intervention group was 5.59 years $(\mathrm{SD}=.47)(M=5.80, \mathrm{SD}=.38$; $M=5.43, \mathrm{SD}=.50$; for boys and girls respectively. The mean age of the control group was 5.84 years $(\mathrm{SD}=.44),(M=5.90, \mathrm{SD}=.45$; $M=5.81, \mathrm{SD}=.44$; for boys and girls respectively). No significant differences were found between the intervention and the control groups in terms of age.

\section{The Intervention}

A program aimed at increasing preschoolers' potency was carried out among the intervention group over a period of 3 months. The program consisted of 1.5-hour-long sessions administered twice a week, for a total of 24 sessions. A practitioner (child psychologist) implemented the intervention. The practitioner met twice with the kindergarten teacher prior to beginning the intervention. In these meetings, the practitioner explained the purpose of the intervention and obtained the teacher's consent to the project. The teacher then met twice with the children's parents in order to explain the goals of the intervention and to obtain their written consent. All of the parents agreed to the participation and videotaping of their children.

The program consisted of experiential, creative activities such as acting, dramatizing, drawing, playing, etc. The activities were designed on the basis of the definition of potency, and so were aimed at facilitating experiences of social support, self-control, group work, and emotional expression. The issues raised and worked on were: confronting uncertain situations, the language of emotions, selfacceptance, communication with others, similarities and differences between the self and others, legitimizing the differences among people, independence, and personal and group decision-making skills. The art techniques used as drama techniques are well recognized as techniques that encourage children's verbal communication through the use of non-verbal communication.

All sessions were videotaped and transcripts were made. These transcripts were then analyzed by separate judges who scored the interactions in order to obtain the interaction quality changes of the children. These analyses are not reported in the current report. As 
32 children in this study attended at least 22 sessions, the following analyses were conducted on the entire sample.

\section{Procedure}

The design of this study was longitudinal as the performance of the same children was assessed at two time intervals, pre- and postintervention (Time 1 and Time 2, respectively). At both Time 1 and Time 2, the LSCT (DiLorenzo, 1975) and the CAMP were administered in semi-structural individual interviews conducted by two trained practitioners (child psychologists). The two tests were administered in random order.

\section{Results}

\section{Preliminary Analysis}

As for the validation sample, a Pearson's correlation analysis revealed a significant positive correlation between the CAMP and the LSCT $(r=.43, p<.001)$. This result provides a further indication of the convergent validity of the CAMP.

An additional correlational analysis revealed that the CAMP scores at Time 1 and Time 2 was significant $(r=.29, p<.05)$. This finding indicates a moderate degree of test/retest reliability.

\section{Potency Intervention Effects}

In order to determine the extent to which intervention affected potency (CAMP), a 2 × 2 (Group $\times$ Time) Repeated Measures MANOVA was conducted. Group (intervention vs. control) served as the independent variable, and scores on the CAMP as the dependent variable. The results revealed no main effect of Group $(F(1,45)=.45$, ns.). However, a significant main effect was found for Time. Potency scored a significant increase at Time $2,(F(1,45)=19.32, p<.001)$. (For Means and Standard Deviations, see Table 1).

A significant Time $\times$ Group interaction was also found, $F(1,45)=6.91, p<.01$. Planned comparisons indicate that this interaction was due to the higher CAMP scores of the intervention group at Time 2 as compared to Time $1, F(1,45)=23.19, p<.001)$. Among 


\section{TABLE 1}

\section{Means and Standard Deviations of the CAMP (Potency) and the LSCT (Self-Esteem) Measures}

\begin{tabular}{|c|c|c|c|c|c|c|c|c|}
\hline \multirow[b]{3}{*}{ Variables } & \multicolumn{4}{|c|}{ Intervention Group $n=32$} & \multicolumn{4}{|c|}{ Control Group $n=34$} \\
\hline & \multicolumn{2}{|c|}{ Time 1} & \multicolumn{2}{|c|}{ Time 2} & \multicolumn{2}{|c|}{ Time 1} & \multicolumn{2}{|c|}{ Time 2} \\
\hline & M & SD & M & SD & M & SD & M & SD \\
\hline CAMP & 4.95 & 10.20 & 13.86 & 4.13 & 9.48 & 7.62 & 11.72 & 6.58 \\
\hline LSCT & 11.18 & 8.59 & 14.45 & 11.33 & 13.69 & 10.59 & 15.88 & 12.26 \\
\hline
\end{tabular}

the control group, no significant time changes in CAMP scores were obtained at Time $2, F(1,45)=1.66$, ns.). The Time $\times$ Group interaction data is presented in Figure 1.

In another $2 \times 2$ (Group $\times$ Time) Repeated Measures MANOVA, the DiLorenzo Self-esteem scores served as the dependent variable and Group (intervention vs. control) as the independent variable. No significant main effect was found for Group $(F(1,45)=.45$, ns. $)$. However, a significant main effect was found for Time. Scores on the Self-Esteem test increased significantly at Time $2(F(1,45)=6.07$, $p$ <.02). No significant Time $\times$ Group interaction was found $(\mathrm{F}(1,45)=.24$, ns. $)$. For Means and Standard Deviations, see Table 1.

\section{Discussion}

The central objective of this study was to examine the impact of Potency-Focused Intervention on preschool students as part of exploring the Child Adaptation Measure of Potency - CAMP - psychometric properties. To achieve this aim, kindergarten children were assessed before and after intervention, using an instrument specifically designed to measure levels of potency in this population (CAMP). They were also compared to children who did not participate in an intervention program. The CAMP measure, developed by 


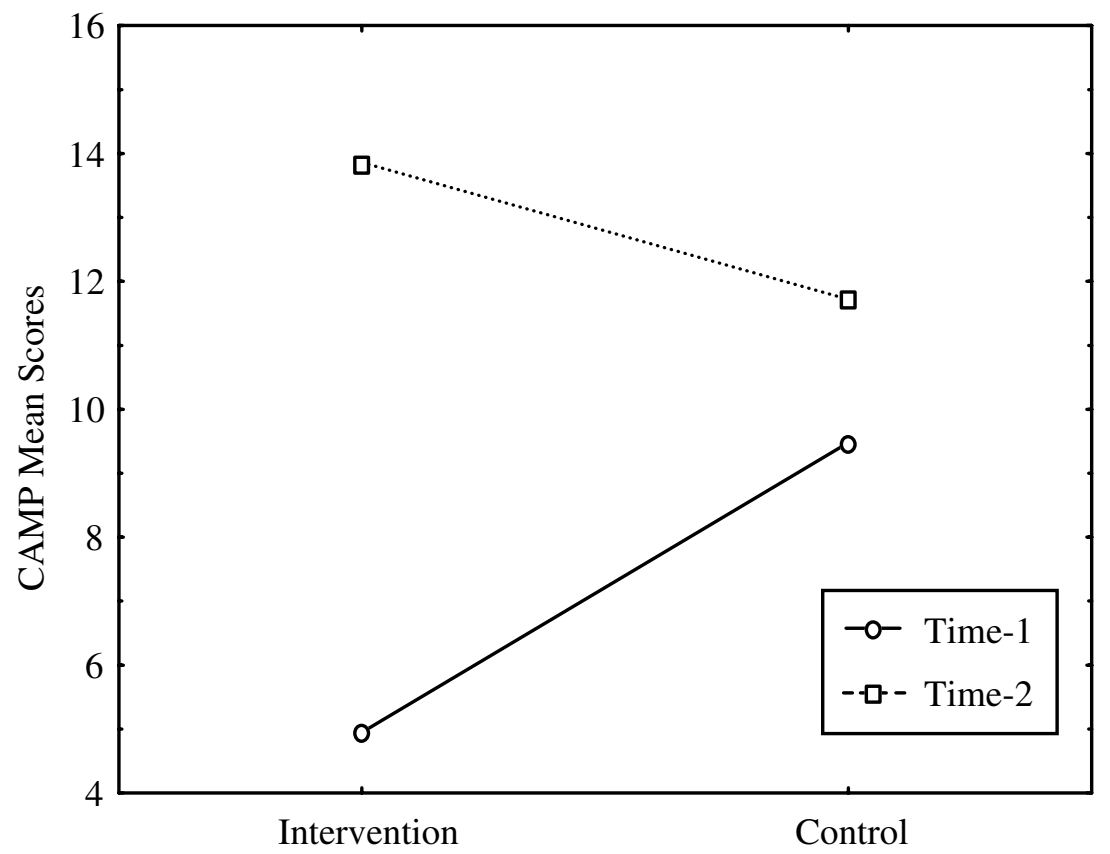

FIGURE 1. The Time $\times$ Group Interaction on the CAMP.

the present authors, is based on an existing scale for assessing potency among adult populations (the Potency Scale; Ben-Sira, 1985). In terms of its psychometric properties, the results revealed that the CAMP was both valid and reliable across several groups of preschool children.

The results also indicate that although there is a correlation between CAMP and a comparison measure used for assessing selfconcept (e.g., the Learner Self-Concept Test-LSCT; DiLorenzo, 1975), the Potency-Focused intervention program enhanced scores on the CAMP, but not on the LSCT. These findings suggest that while selfconcept and potency are similar in some respects, they are different constructs. While both self-concept and potency develop as a result of positive experiences with other people, potency involves experiences with a wide variety of people in the social environment, such as parents, siblings, friends, teachers, etc. In contrast, definitions of self-concept generally focus on the child's relationship to parental 
figures (e.g., Rogers, 1951). Thus, while both types of experience affect the child's perceptions of personal abilities, self-esteem and belief system, potency is the more comprehensive concept. The fact that intervention employed from within the child's wider social environment (the classroom) increased their potency, rather than selfconcept, is commensurate with this theory. Self-concept involves the narrower interaction with the parents, but potency develops as a result of interactions with others. The finding that potency scores increased following intervention, suggests that positive and directed experience with classmates and teachers may strengthen children's belief in the availability of social support and reduce feelings of alienation.

The finding that the Potency-Focused intervention within the educational framework had a positive impact on children (in terms of personal beliefs) is consistent with work done within the school classroom using other types of interventions that had similar goals yet aimed to enhance different psychological constructs such as feelings of competence (Dubas et al., 1998; McCabe, 1998; Weikart \& Schweinhart, 1997). Recent research has shown that participation in extended short-term childhood interventions increases scholastic and social resilience (LaFreniere \& Capuano, 1997; Reynols, 1998; Shure, 1997), defined earlier as competence in these domains (Reynols, 1998). Thus, different types of school-based interventions may be useful for addressing similar goals, such as developing social skills or increasing social tolerance. Improvement in these areas may reduce the risk of long-term effects of stressful life events such as negative emotion, low social involvement, and low personal initiative (Denham \& Burton, 1996; Sameroff, et al., 1998). Early intervention in the preschool years may be particularly effective in preventing long-term negative consequences of stressful life events and traumas, and heighten children's ability to cope with the everincreasing demands of elementary and high school.

While the results of the current study indicate that PotencyFocused Intervention increased preschoolers' potency, the stability of this improvement must be evaluated over time. Therefore, additional follow-up studies are needed to assess the children's levels of potency upon entering elementary school and during the course of later school years. Follow-up studies should not only examine the children's levels of potency, but determine the extent to which potency is associated with the children's academic and social 
achievement. Nevertheless, based on previous findings (e.g., LevWiesel \& Amir, 2000), enhancing potency is likely to strengthen individuals' capability to contain failure rather than learn helplessness behavior.

As mentioned in the introduction of this paper, few quantitative tools exist for measuring ego strengths among preschool children. Most of the available instruments for this population assess symptoms of distress. Moreover, to the best of our knowledge, the majority of the latter measures require intensive training of the tester. The CAMP not only measures an aspect of ego strength, it is also an easily administrated tool requiring a relatively short training period.

However, despite the promising results, it must be noted that the CAMP was evaluated using a fairly small sample. Therefore, additional validation is required using larger groups and a variety of preschool populations. Furthermore, it is important to extend the predictive validity of the CAMP by examining the extent to which it is correlated with other ego strengths as reported by other figures who interact with children such as teachers, practitioners and parents. It is also important to examine if the CMAP scale is able to predict social skills and academic achievement. Another question of interest is whether increases in children's potency are apparent in terms of the overt behavior of the children and their interactions with the adults in their environment. Future research will contribute to a greater understanding of these issues. 
CHILD AND ADOLESCENT SOCIAL WORK JOURNAL

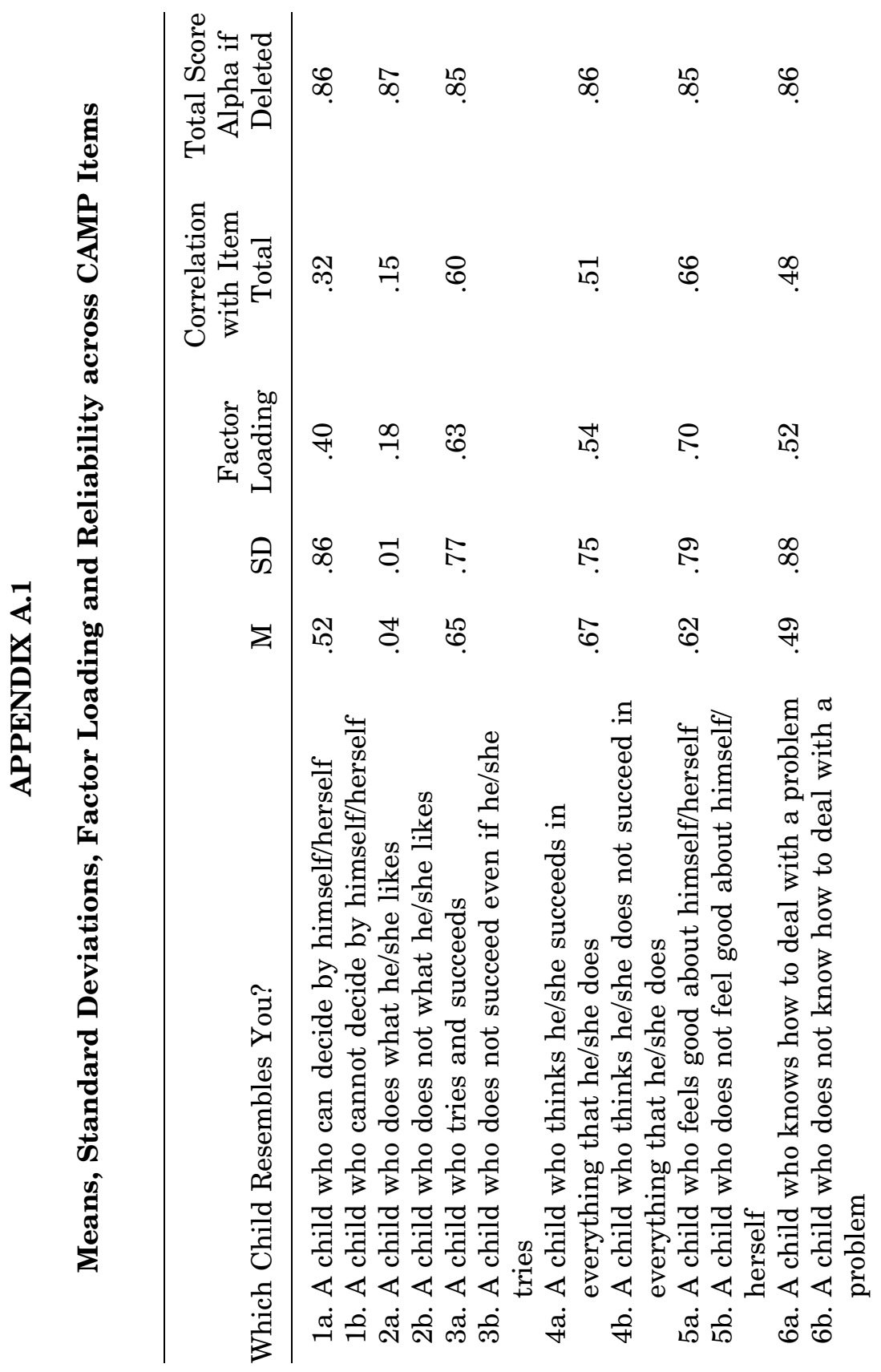


RACHEL LEV-WIESEL, AVI BESSER, AND RENANA LAISH

\begin{tabular}{|c|c|c|c|c|c|c|}
\hline$\infty$. & 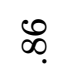 & $\infty$ & $\infty$ & $\stackrel{10}{\infty}$ & $œ$ & $\infty$ \\
\hline กั & F & $\vec{n}$ & 우․ & $\stackrel{20}{2}$ & L & . \\
\hline คి. & $\begin{array}{l}0 \\
19\end{array}$ & ผొ & L & $\infty$ & ชै & 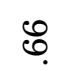 \\
\hline 5 & $\infty$ & \&! & ه & 도. & $\stackrel{\Sigma}{\llcorner}$ & $\mathfrak{N}$ \\
\hline$F$ & مُ & $\stackrel{0}{-1}$ & 施 & ?ִ? & 18 & $?$ \\
\hline
\end{tabular}

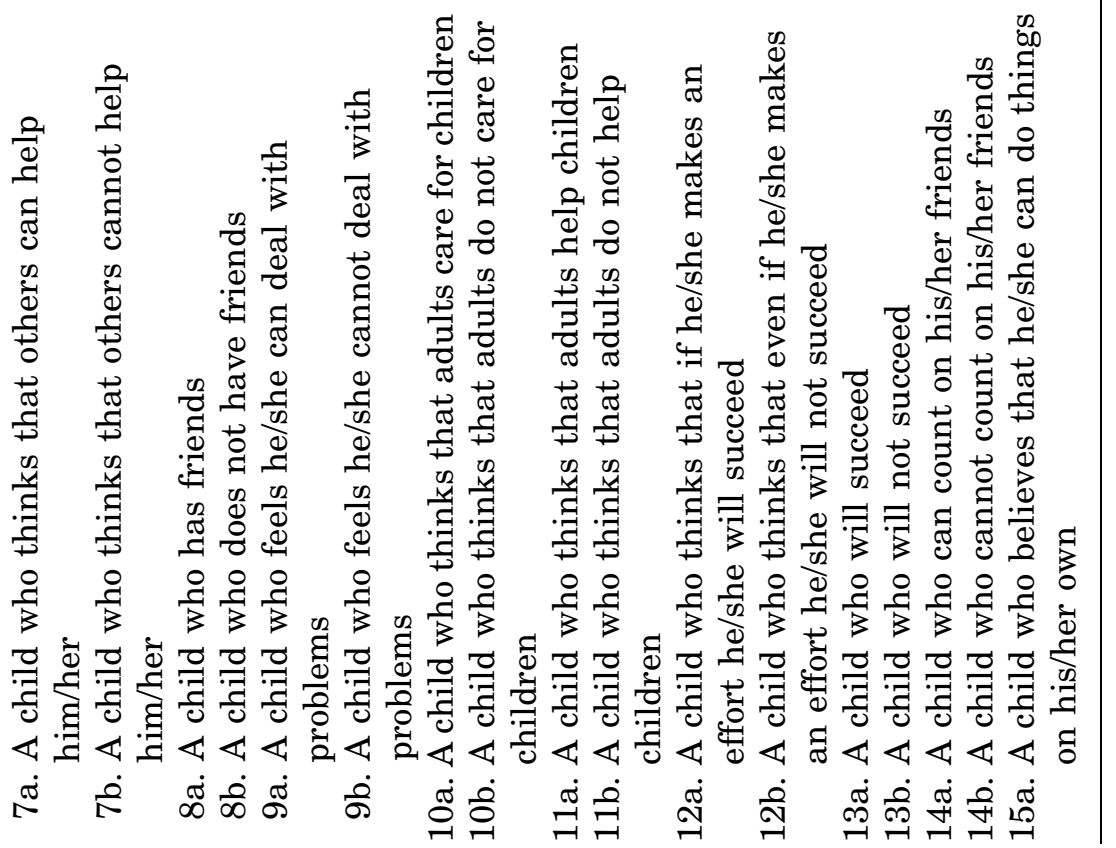


CHILD AND ADOLESCENT SOCIAL WORK JOURNAL

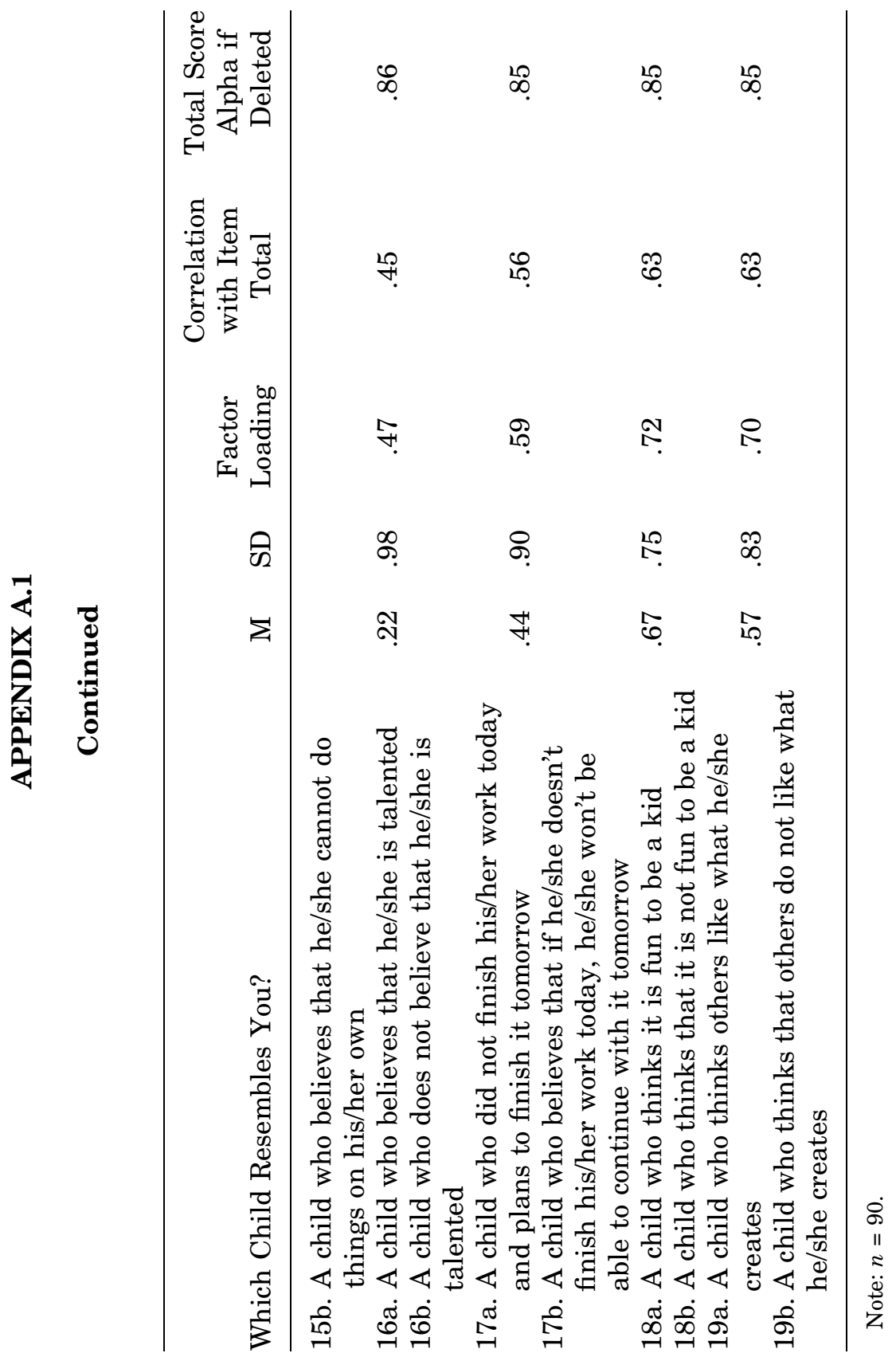




\section{References}

Amir, M., \& Lev-Wiesel, R. (2001). Secondary traumatic stress, psychological distress, sharing of traumatic reminisces and marital quality among spouses of Holocaust child survivors. Journal of Marital and Family Therapy, 27(4), 297-308.

Antonovsky, A. (1979). Health, stress and coping. San Francisco: Jossey Bass.

Antonovsky, A. (1987). Unraveling the mystery of health: How people manage stress and stay well. San-Francisco: Jossey-Bass.

Antonovsky, A. (1991). The structural sources of salutogenic strengths. In C. L. Cooper \& R. Payne (Eds.), Personality and stress: Individual differences in the stress process (pp. 67-104). Chichester, England: Wiley \& Sons.

Antonovsky, A. (1993). The structure and properties of the Sense of Coherence Scale. Social Science and Medicine, 36, 725-733.

Bandura, A. (1982). Self-efficacy mechanism in human agency. American Psychologist, $37,122-147$.

Ben-Sira, Z. (1983). Loss, stress and readjustment: The structure of coping with bereavement and disability. Social Science and Medicine, 17, 1619-1632.

Ben-Sira, Z. (1985). Potency: A stress buffering link in the coping-stress-disease relationship. Social Science and Medicine, 21(4), 397-406.

Ben-Sira, Z. (1989). A readjustment promoting link in Sociology of Health and the rehabilitation of disabled persons. Illness, 11(1), 41-61.

Ben-Sira, Z. (1991). Regression, stress and readjustment aging. New York: Praeger.

Ben-Sira, Z. (1993). Zionism at the close of the twentieth Century. Lewiston: The Edwin Mellen Press.

Bowen, G. L., \& Pittman, J. F. (1995). Introduction. In G. L. Bowen \& J. F. Pittman (Eds.), The work and family interface: Toward a contexual effects perspective (pp. 1-13). Minneapolis: National Council on Family Relations.

Cox, T. (1978). Stress. New York: Macmillan.

Coopersmith, S. (1967). The Antecedents of Self-Esteem. San Francisco: Freeman.

Denham, S. A., \& Burton, R. (1996). A social emotional intervention for at-risk 4-yearolds. Journal of Social Psychology, 34(3), 225-245.

DiLorenzo, L. T. (1975). Lerner self-concept test. New York: Princeton.

Dubas, J. S., Lynch, K. B., Galano, J., Geller, S., \& Hunt, D. (1998). Preliminary evaluation of the resiliency-based preschool substance abuse and violence prevention project. Journal of Drug Education, 28(3), 235-255.

Felker, D. (1979). Building positive self concepts. Minneapolis: Burgess.

Folkman, S., \& Lazarus, R. S. (1991). Coping and emotion. In A. Monat \& R. S. Lazarus (Eds.), Stress and coping, New York: Columbia University Press.

Frazer, M. W. (1997). The ecology of childhood: A multisystems perspective. In M. W. Frazer. (Ed.), Risk and resilience in childhood: An ecological perspective, New York: NASW Press.

Harter, S. (1982). The perceived competence scale for children. Child Development, 53, $87-97$.

Harter, S. (1985). Competence as a dimension of self-evaluation: Toward a comprehensive model of self-worth. In R. L. Leahy (Eds.), The development of self (pp. 55-121). Orlando, FL: Academic Press.

Hepburn, L. R., \& White, R. A. (1990). School dropouts: A two-generation problem. Athens: University of Georgia, Carl Vinson Institute of Government.

Kobasa, S. C. (1979). Stressful life events, personality and health: An inquiry into hardiness. Journal of personality and Social Psychology, 37, 1-12.

LaFreniere, P. J., \& Capuano, F. (1997). Preventive intervention as means of clarifying direction of effects in socialization: Anxious withdrawn preschoolers case. Developmental and Psychopathology, 9(3), 551-564.

Lazarus, R. S., \& Folkman, S. (1984). Stress, appraisal and coping. New York: Springer. 
Lev-Wiesel, R., \& Amir, M. (2000). Posttraumatic stress disorder symptoms, psychological distress, personal resources and quality of life in four groups of Holocaust child survivors. Family Process, 39(4), 445-459.

Lev-Wiesel, R., \& Shamai, M. (1998). Living under the threat of relocation: Spouses' perceptions of the threat and coping resources. Contemporary Family Therapy, 3, $271-295$.

Lev-Wiesel, R. (1998). Coping with stress: Possible forced relocation in the Golan Heights. Israel Journal of Applied Behavioral Science, 34(2), 143-160.

Lewin, K. (1951). Field theory in social science: selected theoretical papers. New York: Harpers.

Mccabe, P. C. (1998). Efficacy of the Enhanced Social Competence Program with typical and language delayed children. Dissertation Abstracts International: Section B: The Sciences and Engineering 58(12-B), 6847.

Martz, L. (1992). Making schools better. New York: Times Books.

Monat, A., \& Lazarus, R. S. (1991). Stress and coping: An anthology. New York: Columbia University Press.

Nowicki, S., \& Duke, M. P. (1974). A preschool and primary internal-external control scale. Developmental Psychology, 10, 874-880.

Pearlin, L. I. (1991). The study of coping. In J. Eckenrode (Eds.), The social context of coping, New York: Plenum.

Richman, J. M., \& Bowen, G. L. (1997). School failure: An Ecological- InteractionalDevelopmental perspective. In M. W. Frazer (Eds.), Risk and resilience in childhood: An ecological perspective, New York: NASW Press.

Richman, J. M., CAMPan, M. V., \& Bowen, G. L. (1995). Recognizing the impact of marital discord and parental depression on children: A family centered approach. In W. L. Coleman \& E. H. Taylor (Eds.), Family Focused pediatrics: Issues, Challenges, and clinical methods (pp. 167-180). Philadelphia: W. B. Saunders.

Rogers, C. (1951). Client centered therapy. Boston: Houghton Mifflin.

Rotter, J. B. (1966). Generalized expectancies for internal versus external control of reinforcement. Psychological Monographs, 60, 11-28.

Reynolds, A. J. (1998). Resilience among Black urban youth: Prevalence, intervention effects, and mechanisms of influence. American Journal of Orthopsychiatry, 68(1), $84-100$.

Sameroff, A. J., Bartko, W. T., Baldwin, C, \& Seifer, R. (1998). Family and social influences on the development of child competence. In M. Lewis \& C. Feiring (Eds.), Families, risk and competence (pp. 161-185). Mahwah, NJ: Lawrence Elbaum.

Seligman, M. E. P. (1975). Helplessness: On depression, development, and death. New York, NY, US: W. H. Freeman/Times Books/ Henry Holt and Co.

Shure, M. B. (1997). Interpersonal cognitive problem solving: Primary prevention of early high-risk behaviors in the preschool and primary years. In G. W. Albee \& T. P. Gullotta (Eds.), Primary prevention works (pp. 262-281). Thousand Oaks, CA: Sage.

Shuval, J. T. (1957). Some persistent effects of trauma: Five years after the Nazi concentration camps. Social Problems, 5, 230-243.

Webster, M. Jr., \& Sobiezek, B. (1967). Sources of self evaluation. A formal theory of significant others and social influence. New York: John Wiley and Sons.

Weikart, D. P., \& Schwinhart, L. J. (1997). High/Scope Perry preschool Program. In G. W. Albee \& T. P. Gullotta (Eds.), Primary prevention works (pp. 237-261). Thousand Oaks, CA: Sage.

Wilie, R. C. (1961). The self concept. Nebraska: University of Nebraska Press.

Wolin, S., \& Wolin, S. (1995). Resilience among youth growing up in substance abusing families. Pediatric Clinics of North America, 42, 415-429.

Yamamoto, K. (1972). The child and his image. Boston: Houghton Miffin. 